\title{
OÚRICURI
}

\section{CENÁRIOS SOBRE INTERNET E SMARTPHONES EM COMUNIDADES RURAIS: UM MAPEAMENTO SISTEMÁTICO}

\author{
Ricardo BITENCOURT ${ }^{1 *}$; Dinani Gomes AMORIM²; Ricardo José Rocha AMORIM ${ }^{3}$ \\ 'Doutorando do Programa de Pós-Graduação em Ecologia Humana e Gestão Socioambiental, \\ Universidade do Estado da Bahia, Juazeiro, BA, Brasil. *Autor Correspondente. E-mail: \\ ricardo.bitencourt@gmail.com
}

${ }^{2}$ Doutora em Electrónica y Computación pela Universidad de Santiago de Compostela (2007). Docente do Programa de Pós-Graduação em Ecologia Humana e Gestão Socioambiental, Universidade do Estado da Bahia, Juazeiro, BA, Brasil. E-mail: dinaniamorim@gmail.com

32 2Doutor em Electrónica y Computación pela Universidad de Santiago de Compostela (2007). Docente do Programa de Pós-Graduação em Ecologia Humana e Gestão Socioambiental, Universidade do Estado da Bahia, Juazeiro, BA, Brasil. E-mail: amorim.ricardo@gmail.com

Recebido: 16.04.2021 Aceito: 01.06.2021

\begin{abstract}
Resumo: Anteriormente muito concentradas em áreas urbanas as Tecnologias da Informação e Comunicação passaram a disponibilizar seus recursos também em áreas rurais. Com a popularização dos smartphones e da internet sem fio, a expansão do acesso passou a ser menos impactada/dificultada em relação aos custos de infraestrutura e manutenção exigidos por conexões tradicionais, como fibra ótica, cabo ou mesmo à rádio. Neste contexto, buscou-se através de um mapeamento sistemático identificar na literatura científica trabalhos que possibilitassem a construção de cenários sobre o uso/presença dessas Tecnologias e suas implicações no cotidiano de comunidades rurais. Os resultados apontam que o uso do smartphone e internet em áreas rurais favorece a comunicação, o desenvolvimento econômico e a participação cidadã, entretanto, apenas o acesso a recursos tecnológicos não é suficiente para se superar a exclusão digital. Por fim, revelase a necessidade do cuidado com o uso excessivo de tecnologias, de modo a se manterem o bemestar mental e em comunidade e o uso crítico dos dispositivos como resposta ao capitalismo informacional.
\end{abstract}

Palavras-chave: Cultura Digital, Ecologia Algorítmica, Captologia, Ecologia Humana.

\section{INTERNET AND SMARTPHONES SCENARIOS IN RURAL COMMUNITIES: A SYSTEMATIC MAPPING}

\begin{abstract}
Previously very concentrated in urban areas, Information and Communication Technologies started to make their resources available also in rural areas. With the popularization of smartphones and wireless internet, the expansion of access started to be less impacted / hampered in relation to the infrastructure and maintenance costs required by traditional connections, such as optical fiber, cable or even to the radio. In this context, it was sought through a systematic mapping to identify works in the scientific literature that would enable the construction of scenarios about the use / presence of these Technologies and their implications in the daily life of rural communities. The results show that the use of smartphones and the internet in rural areas favors communication, economic development and citizen participation, however, only access to technological resources is not enough to overcome the digital divide. Finally, the need to be careful with the excessive use of technologies is revealed, in order to maintain mental and community wellbeing and the critical use of devices in response to informational capitalism.
\end{abstract}

Keywords: Digital Culture, Algorithmic Ecology, Captology, Human Ecology.

Revista Ouricuri, Juazeiro, Bahia, v.11, n.1. p.067-079. jan./jul., 2021. http://www.revistas.uneb.br/index.php/ouricuri | ISSN 2317-0131 


\section{ESCENARIOS DE INTERNET Y SMARTPHONES EN COMUNIDADES RURALES: UN MAPEO SISTEMÁTICO}

Resumen: Las tecnologías de la información y la comunicación, que anteriormente estaban muy concentradas en las zonas urbanas, empezaron a poner sus recursos a disposición también en las zonas rurales. Con la popularización de los teléfonos inteligentes y el internet inalámbrico, la expansión del acceso comenzó a verse menos afectada / obstaculizada en relación a la infraestructura y los costos de mantenimiento que requieren las conexiones tradicionales, como la fibra óptica, el cable o incluso la radio. En este contexto, se buscó a través de un mapeo sistemático identificar trabajos en la literatura científica que permitan la construcción de escenarios sobre el uso / presencia de estas Tecnologías y sus implicaciones en la vida cotidiana de las comunidades rurales. Los resultados muestran que el uso de teléfonos inteligentes e internet en las zonas rurales favorece la comunicación, el desarrollo económico y la participación ciudadana, sin embargo, solo el acceso a los recursos tecnológicos no es suficiente para superar la brecha digital. Finalmente, se revela la necesidad de tener cuidado con el uso excesivo de tecnologías, para mantener el bienestar mental y comunitario y el uso crítico de los dispositivos en respuesta al capitalismo informacional.

Palabras clave: Cultura Digital, Ecología Algorítmica, Captología, Ecología Humana.

\section{INTRODUÇÃO}

A internet tem seu início como uma resposta do governo americano ao projeto Sputnik da antiga União soviética, na década de 50, durante a guerra fria (Abreu, 2009). Nesse período o governo americano criou uma rede experimental de computadores, ARPANET, que anos depois faria surgir a ideia de uma International Network e de uma Interconnected Networks (Almeida, 2005). A rede das redes saiu do objetivo militar e passou a fazer parte de forma significativa na vida humana, interconectando pessoas, centros de pesquisa, instituições e espalhando todo o mundo diversas categorias de informação e mídias (Monteiro, 2001).

Embora durante muito tempo esses acessos estivessem concentrados basicamente computadores, normalmente em instituições, o acesso à rede por particulares passou a ganhar força com o surgimento dos computadores pessoais e mais tarde, de forma significativa, com a abertura das redes e dispositivos móveis na década de 90 . Ao longo da História, a humanidade vem se transformando e as mudanças ocorridas na forma com que as pessoas agem, pensam e se relacionam com as outras buscam uma maior harmonia entre os indivíduos, proporcionando melhor convivência. Essas mudanças podem ser vistas no comportamento social, em especial no que podemos chamar de quebra de tabus sociais, na maioria, tradições antigas baseadas na crença em seres místicos que regem o mundo.

Figura 1 - Parcela da população que usa a internet entre 1990, 2010 e 2017. 


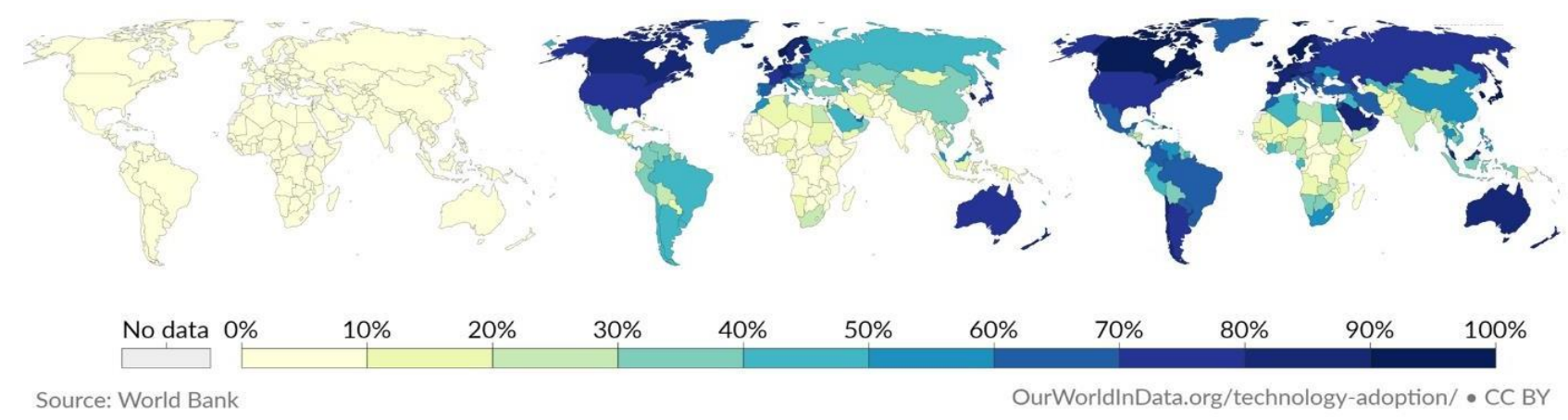

Fonte: OurWorldlnData.org Disponível em https://ourworldindata.org/grapher/share-of-individuals-using-theinternet?time $=$

Segundo a Organização das Nações Unidas (Onu, 2021) 4,1 bilhões de pessoas utilizam a internet. Segundo este relatório, em termos percentuais, $87 \%$ da população de países desenvolvidos já possui acesso à Internet, enquanto nos países em desenvolvimento, esse número chega apenas a 19\%, o que mostra uma diferença abissal no acesso definida pelo poder econômico. O relatório mostra também que $52 \%$ das mulheres estão excluídas do acesso digital, $10 \%$ a mais que os homens (Onu, 2021).

O relatório da International Telecomunication Union (ITU) aponta para a falta de acesso à internet nas áreas rurais. Enquanto $72 \%$ dos domicílios urbanos tinham acesso à Internet doméstica em 2019, apenas 38\% dos rurais tinham o mesmo acesso (Itu, 2020). Dados publicados no Cisco Annual Internet Report (Cisco, 2020), projeta um crescimento de 6\% no número de usuários até 2023. Isso significa que se chegará ao patamar de 5,3 bilhões de pessoas conectadas à Internet, 0 que representará 66\% da população mundial (Quadro 1).

Quadro 1. Usuários de internet por população regional (\%).

\begin{tabular}{|lll|}
\hline \multicolumn{1}{|c|}{ Região } & $\mathbf{2 0 1 8}$ & $\mathbf{2 0 2 3}$ \\
\hline Global & $51 \%$ & $66 \%$ \\
Asia Pacific & $52 \%$ & $72 \%$ \\
Central and Eastern Europe & $65 \%$ & $78 \%$ \\
Latin America & $60 \%$ & $70 \%$ \\
Middle East and Africa & $24 \%$ & $35 \%$ \\
North America & $90 \%$ & $92 \%$ \\
Western Europe & $82 \%$ & $87 \%$ \\
\hline
\end{tabular}

Fonte: Cisco, 2020

$\mathrm{O}$ acesso às redes e aos dispositivos inteligentes fizeram surgir novos paradigmas da relação humana, a exemplo dos conceitos de migrantes digitais e nativos digitais, como identificação das gerações que nasceram antes ou depois da revolução digital (Prensky, 2001) e Cibercultura, que se refere a uma realidade multidirecional, artificial ou virtual incorporada a uma rede global, sustentada por computadores que funcionam como meios de geração de acesso (Levy 2010, p 22). 
O smartphone, por exemplo, passou a ter funções em nosso cotidiano que nada se parecem com o velho habito do telefone analógico. Hoje é possível reservar passagens, pagar contas, realizar transações bancárias, automatizar residências ou monitorar sua a saúde em tempo real. Foi através desse dispositivo e suas conexões que as pessoas passaram a expor mais seus cotidianos, produzir conteúdo e criar estratégias de aceitação em grupo (Nachimuthu, 2012).

A monetização da exposição digital fez surgir negócios só possíveis pela praticidade do uso dos dispositivos. O capitalismo informacional inaugurou circuitos de capital global e um novo modo de acumulação de capital que depende do surgimento da economia imaterial: uma economia que se baseia na digitalização, formalização e matematização do sistema de conhecimento (Karar, 2019).

A expansão da internet possui um caráter inclusivo e emancipatório. A título de exemplo, observa-se a taxa de crescimento da ativação de telefones celulares na África Subsaariana, uma das maiores do mundo e com tendência a alcançar 100\% em 2021 (Eilu, 2018). Para algumas regiões, o acesso à rede mundial de computadores tornou-se tão prioritário que o avanço na disponibilização de acesso à internet aparentemente andou durante certo tempo muito mais rápido do que o fornecimento de água (Martínez-Santos, 2017).

Projetos como a Star link, da empresa SpaceX, a promessa de acesso à internet de alta velocidade é de que será universal. Através de satélites, a empresa pretende fornecer acesso a qualquer usuário no planeta, superando custos com infraestrutura e dificuldades geográficas e este não é o projeto de apenas um provedor.

Muitas empresas de tecnologia acreditam que o futuro da Internet é orbital. Cerca de metade da população do planeta não possui conexão de banda larga com a Internet. A SpaceX pretende colocar cerca de 12.000 Starlinks em órbita baixa da Terra (LEO), para fornecer Internet com velocidade gigabit para a maior parte da superfície da Terra. A rival OneWeb, financiada pela SoftBank do Japão, a fabricante de chips Qualcomm e a Virgin Group de Richard Branson, planeja cobertura global semelhante usando talvez 2.500 satélites LEO (Harris, 2018 p. 10).

Isso posto, manter uma regularidade de estudos sobre relação entre Internet x smartphone, especialmente em contextos rurais, é relevante. Necessita-se observar como essas tecnologias, associadas à cultura urbana, podem afetar o cotidiano dessas regiões e como os usuários criam estratégias de uso, seja em benefício próprio, seja em benefício da comunidade da qual fazem parte. Deste modo, o presente trabalho em forma de mapeamento sistemático pretende apresentar cenários sobre a temática da Internet e dispositivos móveis no contexto rural, a partir da literatura científica, visando responder a seguinte questão principal: Como é reportada na literatura científica a temática da internet e celular em contexto rural?

\section{O PROCESSO DO MAPEAMENTO SISTEMÁTICO}


Geralmente as pesquisas científicas se iniciam com uma revisão da literatura. Entretanto, apesar de fundamental, nem toda revisão é passível de replicação por outros pesquisadores por possuírem critérios subjetivos definidos por seus autores. Outra possibilidade é o mapeamento ou a revisão sistemática, onde é possível se estabelecer um rigor na busca pela literatura científica permitindo que outros interessados possam avaliar e repetir o processo.

O mapeamento sistemático é uma estratégia complementar à revisão sistemática, e busca identificar que evidências estão disponíveis em uma área de pesquisa. Tem como vantagem o fornecimento de informações sobre um determinado fenômeno e a possibilidade de cominação através de técnicas meta-analíticas, mas não exclui a possibilidade de vieses analíticos (Kitchenham, 2004).

Utilizou-se como ferramenta auxiliar o State of the Art through Systematic Review (StArt), software desenvolvido pelo Laboratório de Pesquisa em Engenharia de Software (LAPES), da Universidade Federal de São Carlos, o que possibilitou a organização mais eficaz do Planejamento, Execução e Sumarização. Também permite que o usuário elabore um relatório final sobre a revisão realizada, podendo a todo momento acessar as informações extraídas de cada estudo na etapa de extração de informações (Hernandes, 2010).

\section{Planejamento}

No planejamento foi construído o protocolo da revisão onde foram estabelecidas as estratégias de busca e os critérios a serem utilizados no processo. O protocolo é a etapa mais importante do mapeamento sistemático, pois é ele quem vai definir a qualidade do trabalho (Kitchenham e Charters, 2007) e será a base para a realização da execução (identificação e extração dos estudos) e sumarização (construção do relatório final).

A partir da questão principal, buscou-se identificar como os trabalhos estão concentrados, por base de publicação (P1), quais as abordagens (P2), quais os tipos de pesquisa (P3), que estratégias de campo são empregadas na pesquisa (P4) e quais as principais conclusões do trabalho (P5). As palavras-chave utilizadas nas buscas foram Internet, Rural e Cell phone, este último com seus sinônimos ou traduções Mobile Phone; Smartphone; Celular; Teléfono Movil.

Em seguida (Quadro 2), passou-se à construção dos critérios de inclusão e exclusão, importantes para o direcionamento da revisão ao seu objetivo, evitando a utilização de trabalhos que não estejam relacionados com o tema.

Quadro 2. Critérios de inclusão e exclusão

\begin{tabular}{|c|c|}
\hline Inclusão & Exclusão \\
\hline Acesso integral à produção & $\begin{array}{l}\text { Estudos em contextos urbanos ou não identificados } \\
\text { como de contexto rural }\end{array}$ \\
\hline $\begin{array}{l}\text { Indicar estudos sobre impactos atribuídos ao } \\
\text { uso ou presença do celular em comunidades } \\
\text { rurais }\end{array}$ & Não permitir acesso completo ao trabalho \\
\hline $\begin{array}{l}\text { Tratar claramente das palavras-chaves da } \\
\text { busca }\end{array}$ & $\begin{array}{l}\text { Não é um artigo publicado em periódico científico ou } \\
\text { estar fora do período de } 2010-2020 \\
\text { Não possui relação com o objetivo da revisão }\end{array}$ \\
\hline
\end{tabular}

Revista Ouricuri, Juazeiro, Bahia, v.11, n.1. p.067-079. jan./jul., 2021. http://www.revistas.uneb.br/index.php/ouricuri | ISSN 2317-0131 
Ausência de ao menos três palavras-chave no título, abstract ou keyword (internet, rural ou alguma outra relacionada ao Smartphone)

Fonte: Próprios autores. 2021.

As buscas foram realizadas nas bases DOAJ, ERIC, IEEE, JSTOR, SAGE, SCIELO, SCIENCE DIRECT, SCOPUS e WEB OF SCIENCE elegidas por serem amplamente reconhecidas pela comunidade científica, permitirem o alcance do objetivo proposto por esta revisão e por possibilitarem melhor organização das referências encontradas para o tratamento dos dados. Assim, para evitar redundâncias no levantamento e manter um padrão na extração dos dados, o que tornaria a busca mais trabalhosa do que precisa, optou-se por não usar Portais como Google Scholar.

Utilizou-se a string de busca Internet AND ("cell phone" OR "mobile phone" OR "smartphone" OR "Celular" OR "teléfono móvil") AND Rural e do resultado foram selecionados artigos revisados por pares, publicados no período de 2010 a 2020, em português, inglês ou espanhol. A aplicação da string obedeceu aos critérios de estrutura de cada base, conforme quadro 3.

Quadro 3. Crítérios de inclusão e exclusão

\begin{tabular}{|c|c|}
\hline $\begin{array}{l}\text { Base de } \\
\text { dados }\end{array}$ & String de busca aplicada \\
\hline DOAJ & $\begin{array}{c}\text { Internet AND ("cell phone" OR "mobile phone" OR "smartphone" OR "Celular" } \\
\text { OR "teléfono móvil") AND Rural }\end{array}$ \\
\hline ERIC & $\begin{array}{c}\text { Internet AND ("cell phone" OR "mobile phone" OR "smartphone" OR "Celular" } \\
\text { OR "teléfono móvil") AND Rural }\end{array}$ \\
\hline IEEE & $\begin{array}{c}\text { Internet AND ("cell phone" OR "mobile phone" OR "smartphone" OR "Celular" } \\
\text { OR "teléfono móvil") AND Rural }\end{array}$ \\
\hline JSTOR & $\begin{array}{c}\text { (((Internet) AND (("cell phone" OR "mobile phone" OR "smartphone" OR } \\
\text { "Celular" OR "teléfono móvil"))) AND (Rural)) }\end{array}$ \\
\hline SAGE & $\begin{array}{c}\text { Internet AND ("cell phone" OR "mobile phone" OR "smartphone" OR "Celular" } \\
\text { OR "teléfono móvil") AND Rural }\end{array}$ \\
\hline SCIELO & $\begin{array}{c}\text { Internet AND ("cell phone" OR "mobile phone" OR "smartphone" OR "Celular" } \\
\text { OR "teléfono móvil") AND Rural }\end{array}$ \\
\hline $\begin{array}{l}\text { SCIENCE } \\
\text { DIRECT }\end{array}$ & $\begin{array}{c}\text { Internet AND ("cell phone" OR "mobile phone" OR "smartphone" OR "Celular" } \\
\text { OR "teléfono móvil") AND Rural }\end{array}$ \\
\hline SCOPUS & $\begin{array}{c}\text { Internet AND ("cell phone" OR "mobile phone" OR "smartphone" OR "Celular" } \\
\text { OR "teléfono móvil") AND Rural }\end{array}$ \\
\hline $\begin{array}{l}\text { WEB OF } \\
\text { SCIENCE }\end{array}$ & $\begin{array}{c}((((\text { Internet) AND (("cell phone" OR "mobile phone" OR "smartphone" OR } \\
\text { "Celular" OR "teléfono móvil"))) AND (Rural))) }\end{array}$ \\
\hline
\end{tabular}

\subsection{Seleção inicial dos estudos.}

As buscas nas bases resultaram na identificação de 787 trabalhos, distribuídos por motor de busca, conforme Quadro 4.

Quadro 4. Estudos encontrados por base de dados. 


\begin{tabular}{|cccccccccc|}
\hline $\begin{array}{c}\text { Base de } \\
\text { dados }\end{array}$ & DOAJ & ERIC & IEEE & JSTOR & SAGE & SCIELO & $\begin{array}{c}\text { SCIENCE } \\
\text { DIRECT }\end{array}$ & SCOPUS & WEB OF \\
Quantidade & 2 & 21 & 3 & 249 & 23 & 4 & 145 & 245 & 95 \\
\hline
\end{tabular}

Fonte: Próprios autores, 2021

Uma vez organizados, aplicaram-se os critérios de inclusão e exclusão, onde foram rejeitados os artigos que tivessem ao menos um critério de exclusão. A aplicação dos critérios foi realizada em duas rodadas, uma na fase de seleção inicial e outra na fase de extração.

A figura 2 apresenta o resultado da avaliação inicial dos trabalhos. Foram descartados 104 trabalhos por duplicidade e 648 por se encaixarem em algum critério de exclusão após a leitura dos títulos, abstract e palavras-chave de cada trabalho.

Figura 2 - Gráfico da seleção inicial dos artigos

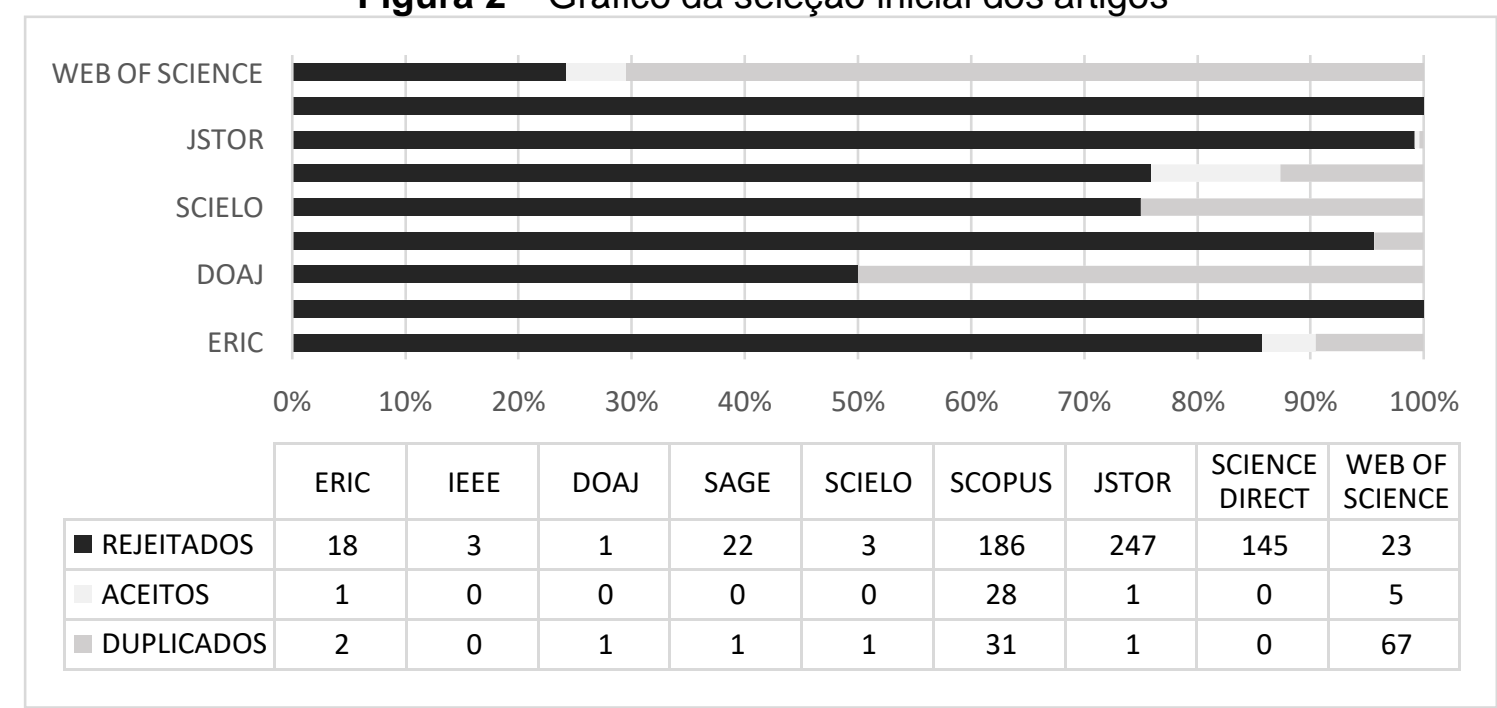

Fonte: Próprios autores, 2021

Os 35 trabalhos que aprovados na seleção inicial foram para a faze de extração ondo foram lidos integralmente e submetidos novamente aos critérios de exclusão.

\section{Extração}

Os 35 trabalhos selecionados para a fase de extração foram lidos integralmente. Após nova rodada de aplicação dos critérios de exclusão, 12 destes foram rejeitados por não possuírem relação com o objetivo da revisão (Figura 3).

Figura 3. Gráfico dos trabalhos selecionados e rejeitados no processo de extração 


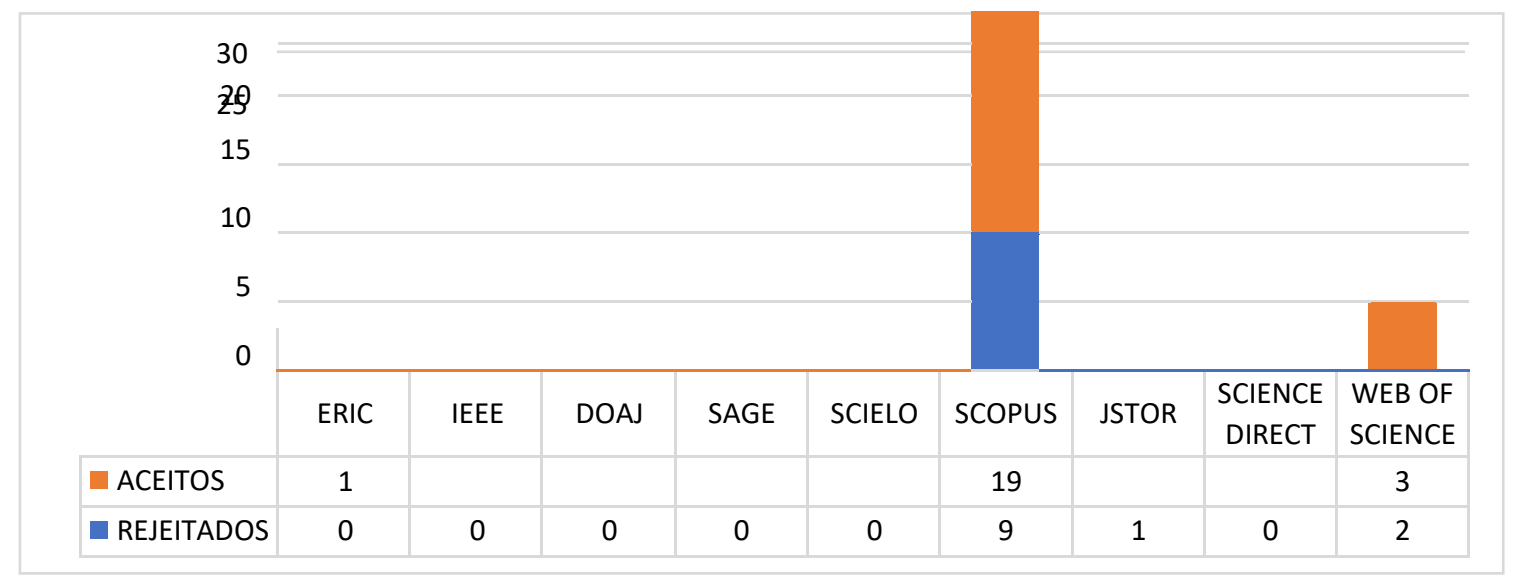

Fonte: Próprios autores, 2021

Entre os trabalhos selecionados (Quadro 7), estão publicações direcionadas especialmente aos continentes africano e asiático e apresentam impactos da implantação das tecnologias móveis em áreas rurais. Apresentam referências que provocam o debate sobre o capitalismo informacional, desenvolvimento econômico, decolonialidade acerca das Tecnologias da Informação e Comunicação, bem como Saúde e protagonismo feminino.

Quadro 5 - Descrição dos artigos selecionados na fase de Extração

\begin{tabular}{|c|c|c|}
\hline Title & Authors & Year \\
\hline Algorithmic Capitalism and the Digital Divide in Sub-Saharan Africa & Karar, Haytham & 2019 \\
\hline $\begin{array}{l}\text { An assessment of mobile internet usage in a rural setting of a developing } \\
\text { country }\end{array}$ & Eilu, E & 2018 \\
\hline Challenges for the next level of digital divide in rural Indonesian communities & $\begin{array}{l}\text { Onitsuka, K; } \\
\text { Hidayat, A. R. R. } \\
\text { T.; Huang, W }\end{array}$ & 2018 \\
\hline $\begin{array}{l}\text { Digital divide and social cleavage: Case studies of ICT usage among } \\
\text { peasants in contemporary China }\end{array}$ & Guo, Y; Chen, P & 2011 \\
\hline $\begin{array}{l}\text { Digital literacy of women as the cadres of community empowerment in rural } \\
\text { areas }\end{array}$ & Hufad, A; et al. & 2019 \\
\hline Epidemiology of technology addiction among school students in rural India & $\begin{array}{l}\text { Jamir, Limalemla; } \\
\text { et al. }\end{array}$ & 2019 \\
\hline $\begin{array}{l}\text { Examining linkages between Smart Villages and Smart Cities: Learning from } \\
\text { rural youth accessing the internet in India }\end{array}$ & $\begin{array}{l}\text { Fennell, Shailaja; } \\
\text { et al. } \\
\text { Felippi, Ã. C. T.; }\end{array}$ & 2018 \\
\hline Icts in family farming: Its uses and acquisition in regions of southern Brazil & $\begin{array}{l}\text { Deponti, C M; } \\
\text { Dornelles, M }\end{array}$ & 2017 \\
\hline $\begin{array}{l}\text { Influence of socio-demographic factors on mobile phone adoption in rural } \\
\text { Bangladesh: Policy implications }\end{array}$ & Alam, G M; et al. & 2019 \\
\hline $\begin{array}{l}\text { Information and communication technology for fisheries industry development } \\
\text { in Malaysia }\end{array}$ & $\begin{array}{l}\text { Omar, Siti } \\
\text { Zobidah; et al. }\end{array}$ & 2011 \\
\hline Kenyan Women's Rural Realities, Mobile Internet Access, and "Africa Rising" & $\begin{array}{l}\text { Wyche, Susan; } \\
\text { Olson, Jennifer }\end{array}$ & 2018 \\
\hline $\begin{array}{l}\text { Mobile phones, household welfare, and women's empowerment: evidence } \\
\text { from rural off-grid regions of Bangladesh }\end{array}$ & $\begin{array}{l}\text { Hossain, Monzur; } \\
\text { Samad, Hussain }\end{array}$ & 2020 \\
\hline $\begin{array}{l}\text { Prevalence and co-occurrence of compulsive buying, problematic Internet and } \\
\text { mobile phone use in college students in Yantai, China: relevance of self-traits }\end{array}$ & $\begin{array}{l}\text { Jiang, Zhaocai; } \\
\text { Shi, Mingyan }\end{array}$ & 2016 \\
\hline $\begin{array}{l}\text { Problematic Internet use and its associations with health-related symptoms } \\
\text { and lifestyle habits among rural Japanese adolescents }\end{array}$ & Kojima, R; et al. & 2019 \\
\hline $\begin{array}{l}\text { Rural families in tobacco growing areas and their daily interaction with } \\
\text { communication technologies: the reorganization of personal and family life }\end{array}$ & $\begin{array}{l}\text { Escosteguy, Ana } \\
\text { Carolina; et al. }\end{array}$ & 2015 \\
\hline
\end{tabular}


Rurality and information and communication technologies: the new ways of living of farming families
Escosteguy, Ana Carolina D; 
Small town in the internet society: Chapleau is no longer an island

Technology Is an Embedded Agent of Cultural Impact

The family politics of new media domestication: an ethnographic study of

mobile phones' influences on rural adolescents' socialization in a central

Chinese town

The relationship between smartphone use and subjective well-being in rural

China

Use of computer and cellular phone technology by older rural adults

Water versus wireless coverage in rural Mali: Links and paradoxes

You Are Too Out!: A mixed methods study of the ways in which digital divides articulate status and power in China

$\begin{array}{ll}\text { Trevisan Felippi, } & \\ \text { Angela Cristina } & \\ \quad \text { Collins, J L; } & 2010 \\ \quad \text { Wellman, B } & 2012 \\ \text { Nachimuthu, K } & \\ \text { Guan, Cheng-yun; } & \\ \quad \text { Tang, Jia-mei; } & 2020 \\ \quad \text { Wang, Min } & \\ \quad \text { Nie, P; et al. } & 2020 \\ \text { O'Brien, T R; et al. } & 2014 \\ \text { Martínez-Santos, } & 2017 \\ \quad \text { P. } & \\ \quad \text { Xiao, Z } & 2020\end{array}$

Fonte: Próprios autores, 2021

Após a leitura, verificou-se que 51\% apontavam ser de abordagem qualitativa, 37\% quantitativo e $11 \%$ de abordagem mista. Boa parte dos trabalhos apontava para trabalhos de campo e aplicação de questionários. Poucos trabalhos trouxeram relatos de entrevistas, ainda que tenham apresentando trabalhos de campo contato direto com os participantes. A frequência da utilização de abordagens qualitativas também reforçou a importância dessa estratégia para os estudos da temática.

\section{ANÁLISE}

As produções apresentaram um panorama bastante amplo sobre a relação entra a Internet, smartphones em contextos rurais, o que demonstra que os fenômenos associados a ela exigem cada vez mais a atenção. Evidenciou-se que a emancipação dos sujeitos, a partir do aos recursos tecnológicos, não diminui a exclusão digital. Dessa forma, o capitalismo algoritmo enquanto favorece o acesso, também amplia a exclusão digital, especialmente quando se comparam o urbano com o rural (Onitsuka, et al., 2018; Karar, 2019;), apesar de essas passarem a compor a paisagem rural, ocupando os espaços do cotidiano (Escosteguy, et al., 2015).

Entretanto, mesmo assumindo um risco de homogeneização no espaço digital, favorecido pelo capitalismo algorítmico (Karar, 2019), há que se considerar a capacidade de os sujeitos construírem novos sentidos a partir de sua competência cultural, viabilidade técnica, necessidades e possibilidades (Escosteguy, et al., 2015).

A utilização das TICs em áreas rurais tem um papel importante para a autonomia e protagonismo femininos (Wyche; Olson, 2018). As mulheres incrementam suas habilidades de alfabetização digital (leitura e escrita) aprendendo e se comunicando continuamente com outras pessoas (Hufad et al., 2019). O uso do telefone celular, por exemplo, favorece a mobilidade, realização de negócios, educação e saúde, atuando como uma importante fonte de informação e articulando uma rede que facilita o empreendimento feminino (Hossain; Samad, 2020), o que corrobora com a análise de Wyche e Olson (2018) quando reafirmam o lugar das mulheres nesse 
processo e também como o acesso ao telefone celular possibilita melhores condições a elas, especialmente ao acesso à informação.

Outro ponto revela que mesmo com a influência comunicacional externa, os contextos locais também podem definir os usos e direcionamentos das tecnologias, destoando de uma expectativa geral ou de um local comum de uso (Eilu, 2018; Xiao, 2019). Essas diferenças, como qualquer componente cultural, emergem não apenas entre gerações diferentes, mas também em sujeitos contemporâneos, o que reforça a necessidade de ampliação do acesso com ações que favoreçam a autonomia dos usuários, Sejam eles nativos ou imigrantes digitais (Onitsuka, et al., 2018). Diante disso, é imperativo que os investimentos em educação e desenvolvimento humano nas áreas rurais precisa acompanhar a adoção em larga escala das Tecnologias da Informação e Comunicação (Alam et al., 2019).

A presença das TICs influencia significativamente a comunicação e o estilo de vida de quem vive em áreas rurais. Isso vai desde a manutenção do contato com parentes mais distantes, passando pela concentração do lazer e entretenimento através dos dispositivos e a ampliação da rede de negócios, chegando ao acesso ao "mundo externo". Assim, reforça-se a importância de substituir a dicotomia sociedade $\mathrm{x}$ tecnologia pelo paradigma sociedade-tecnologia, visto que essas estão mutuamente integradas (Guo; Chen, 2011) e fortalecendo a contemporaneidade como reflexo desse processo histórico, onde as novas mídias têm viabilizado novas formas de sociabilidade, não exclusivas dos espaços urbanos (Escosteguy et al., 2017)

O acesso à telefonia móvel, por exemplo, pode favorecer ao desenvolvimento em áreas rurais de aldeias inteligentes, caracterizadas pelo uso das TICs para melhorar a educação e as perspectivas de emprego. Espera-se que, dessa forma, os jovens de áreas rurais possam construir alternativas econômicas e que se forneça à comunidade uma alternativa de governança para empoderamento, a exemplo de casos da Índia rural (Fennell, et al. 2018). Na mesma direção, Felippi (et al., 2017) demonstram que as TICs têm reduzido distâncias no cotidiano rural, favorecendo a relação com outros, especialmente urbanos, e reduzindo uma lacuna existente no acesso à informação. Ainda que se tenha acesso a diversos dispositivos tecnológicos, o celular é a principal (quando não, o único) TIC disponíveis para a maioria das famílias rurais, independentemente de sua renda (Alam, et al., 2019).

O acesso à tecnologia tem estimulado crescimento econômico, possibilitando outras narrativas em regiões com menos recursos e mostra que o uso de telefones celulares pode favorecer ao aumento da renda familiar (Omar, 2011; Wyche e Olson , 2018); Nie, et al., 2020). Vale ressaltar que mesmo com acesso a diversos bens culturais mediados pela tecnologia, é no contexto local onde as necessidades físicas e sociais do sujeito são supridas. "Uma comunidade remota permanecerá remota" e o acesso à rede mundial permite essa vivência mundial, independentemente da localização geográfica (Collins; Wellman, 2010) 
Evidenciaram-se também alertas sobre a interrelação entre tecnologia e saúde, como problemas associados à dependência e vício nos dispositivos, o que causa prejuízos especialmente aos mais jovens, contribuindo para o baixo desempenho acadêmico e depressão, especialmente dos mais jovens (Jamir et al. 2019). Jiang e Mingyan (2016) relatam sobre problemas relacionados à compulsão e uso problemático da internet. Em seu trabalho revelam que pessoas que usam telefone celular para navegar na Internet apresentam maior risco de desenvolver uso problemático da internet do que os colegas que usam o computador. Kojima et al. (2019) complementam essa preocupação de que o uso problemático da internet pode estar relacionado à perda de sono, prejuízos nos estudos e aumentando os sintomas de depressão. Evivendia-se, portanto, a importância do acompanhamento dos pais e da conscientização dos jovens sobre os perigos que envolvem o acesso, exposição e consumo no mundo digital e como isso pode afetar negativamente o indíviduo e a comunidade na qual se está inserido (Nachimuthu, 2012; Guan, et al., 2020).

Por fim, destaque-se que a tecnologia também pode trazer benefícios. Esses recursos dão suporte à telemedicina, facilitando o acesso a cuidados médicos, especialmente para os idosos e para queles que tem recursos limitados para isso. Pra que isso ocorra, é imprescindível que se rompa as barreiras de conhecimento relacionado ao uso dos dispositivos e se melhore a infraestrutura de acesso à internet, especialmente a móvel (O'Brien et al., 2014; Escosteguy, et al., 2015; Wyche; Olson, 2018).

\section{CONSIDERAÇÕES FINAIS}

O mapeamento sistemático possibilitou uma busca ordenada e segura para a identificação da abrangência de temas de pesquisa. No processo identificou-se um número significativo de trabalhos que favoreceram a apresentação de cenários sobre a presença/uso da Internet e Smartphone em contextos rurais.

Foi possível evidenciar cenários da influência dos Smartphone e internet em contextos rurais, revelando a necessidade de atualização constante destas pesquisas, dado que as tecnologias de comunicação mudam constantemente. Verificou-se que apesar dos dispositivos trazerem consigo interfaces e conteúdos externos, os contextos locais são importantes para as decisões dos usuários sobre consumo e produção de conteúdo.

O acesso à internet e todas as possibilidades que ela proporciona ainda é um privilégio urbano e dos países desenvolvidos. Apesar das limitações impostas por um capitalismo informacional, identificaram-se nichos de desenvolvimento nos espaços rurais, favorecidos especialmente com a ampliação do acesso à internet através de dispositivos celulares.

$\mathrm{O}$ acesso em áreas rurais favoreceu o empoderamento feminino e viabilizou o desenvolvimento, mesmo que tímido, de ecossistemas econômicos diversos que fazem da divulgação/exposição dessas realidades um passo importante na melhoria das realidades locais. 
O impacto da presença/uso dessas tecnologias na saúde dos usuários revelou-se um problema bastante complexo visto que, apesar de baratear a disponibilidade de atendimento em saúde básica em regiões de difícil atendimento, pode estar relacionado a danos à saúde mental e ao bem-estar social em áreas rurais.

\section{REFERÊNCIAS}

Abreu, K.C.K. História e usos da Internet. BOCC-Bliblioteca Online de Ciências da Comunicação, p. 1-9, 2009.

Alam, G. M. Influence of socio-demographic factors on mobile phone adoption in rural Bangladesh: Policy implications. Information Development, v. 35, n. 5, p. 739-748, 2019.

Almeida, J. M. F. Breve história da Internet. 2005.

Cisco, U. Cisco annual internet report (2018-2023) white paper. 2020. Acessado em 10/01/2021 Disponível em: https://bit.ly/3msP91g

Collins, J. L.; Wellman, B. Small town in the Internet society: Chapleau is no longer an island. American Behavioral Scientist, v. 53, n. 9, p. 1344-1366, 2010.

Eilu, E. An Assessment of Mobile Internet Usage in a Rural Setting of a Developing Country. International Journal of Mobile Computing and Multimedia Communications (IJMCMC), v. 9, n. 2, p. 47-59, 2018.

Escosteguy, A. C.; Trevisan Felippi, A. C. Rurality and information and communication technologies: the new ways of living of farming families. Cuadernos del claeh-centro latinoamericano de economia humana, v. 36, n. 106, p. 129-150, 2017.

Escosteguy, A. C. et al. Rural families in tobacco growing areas and their daily interaction with communication technologies: the reorganization of personal and family life. CHASQUI-REVISTA LATINOAMERICANA DE COMUNICACION, n. 130, p. 329-345, 2015.

Felippi, A. C. T; Deponti, C. M.; Dornelles, M. TICs na agricultura familiar: os usos e as apropriações em Regiões do Sul do Brasil. Revista Brasileira de Gestão e Desenvolvimento Regional, v. 13, n. 1, 2017.

Fennell, S. et al. Examining linkages between Smart Villages and Smart Cities: Learning from rural youth accessing the internet in India. Telecommunications Policy, v. 42, n. 10, p. 810-823, 2018.

Guan, C.; Tang, J.; Wang, M. The family politics of new media domestication: an ethnographic study of mobile phones' influences on rural adolescents' socialization in a central Chinese town. Asian Journal of Communication, v. 30, n. 1, p. 1-19, 2020.

Guo, Y; Chen, P. Digital divide and social cleavage: Case studies of ICT usage among peasants in contemporary China. The China Quarterly, p. 580-599, 2011.

Harris, M. Tech giants race to build orbital internet [news]. IEEE Spectrum, v. 55, n. 6, p. 10-11, 2018.

Hernandes, E. et al. Avaliação da ferramenta StArt utilizando o modelo TAM e o paradigma GQM. In: Proceedings of 7th Experimental Software Engineering Latin American Workshop (ESELAW 2010). 2010. p. 30.

Hossain, M; Samad, H. Mobile phones, household welfare, and women's empowerment: evidence from rural off-grid regions of Bangladesh. Information Technology for Development, p. 1-17, 2020.

Hufad, A. et al. Digital Literacy of Women as the Cadres of Community Empowerment in Rural Areas. International Journal of Innovation, Creativity and Change. www.ijicc.net Volume 9, Issue 7. p276-288, 2019 
International Telecommunication Union (ITU). Measuring digital development Facts and figures. Acessado em 10/01/20212020. Disponível em: https://www.itu.int/en/ITUD/Statistics/Documents/facts/FactsFigures2020.pdf

Jamir, L. et al. Epidemiology of technology addiction among school students in rural India. Asian journal of psychiatry, v. 40, p. 30-38, 2019.

Jiang, Z.; Shi, M. Prevalence and co-occurrence of compulsive buying, problematic Internet and mobile phone use in college students in Yantai, China: relevance of self-traits. BMC public health, $v$. 16, n. 1, p. 1-8, 2016.

Karar, H. Algorithmic Capitalism and the Digital Divide in Sub-Saharan Africa. Journal of Developing Societies, v. 35, n. 4, p. 514-537, 2019.

Kitchenham, B. Procedures for performing systematic reviews. Keele, UK, Keele University, v. 33, n. 2004, p. 1-26, 2004.

Kitchenham, B; Charters, S. Guidelines for performing systematic literature reviews in software engineering. 2007.

Kojima, R. et al. Problematic Internet use and its associations with health-related symptoms and lifestyle habits among rural Japanese adolescents. Psychiatry and Clinical Neurosciences, v. 73, n. 1, p. 20-26, 2019.

Martínez-Santos, P. et al. Water versus wireless coverage in rural Mali: links and paradoxes. Water, v. 9, n. 6, p. 375, 2017.

Monteiro, L. A internet como meio de comunicação: possibilidades e limitações. In: Congresso Brasileiro de Comunicação. 2001.

Nachimuthu, K. Technology Is an Embedded Agent of Cultural Impact. Journal of Educational Technology, v. 9, n. 1, p. 23-30, 2012.

Nie, P.; Ma, W.; Sousa-Poza, A. The relationship between smartphone use and subjective well-being in rural China. Electronic Commerce Research, p. 1-27, 2020.

O'brien, T. R. et al. Use of computer and cellular phone technology by older rural adults. CIN: Computers, Informatics, Nursing, v. 32, n. 8, p. 390-396, 2014.

Omar, S. Z. et al. Information and communication technology for fisheries industry development in Malaysia. African Journal of Agricultural Research, v. 6, n. 17, p. 4166-4176, 2011.

Onitsuka, K; hidayat, AR. R. T.; Huang, W. Challenges for the next level of digital divide in rural Indonesian communities. The Electronic Journal of Information Systems in Developing Countries, $v$. 84, n. 2, p. e12021, 2018.

Organização das Nações Unidas (ONU). World social report 2020: inequality in a rapidly changing world. Disponível em: https://www.un.org/development/desa/dspd/wpcontent/uploads/sites/22/2020/02/World-Social-Report2020-FullReport.pdf. Acessado em: $01 / 03 / 2021$

Levy. P. Cibercultura. Editora 34, 2010.

Prensky, M. Nativos digitais, imigrantes digitais. On the horizon, v. 9, n. 5, p. 1-6, 2001.

Wyche, S; Olson, J. Gender, Mobile, and Mobile Internet| Kenyan Women's Rural Realities, Mobile Internet Access, and "Africa Rising". Information Technologies \& International Development, v. 14, p. 15, 2018.

Xiao, Z. 'You Are Too Out!': A mixed methods study of the ways in which digital divides articulate status and power in China. Information Development, v. 36, n. 2, p. 257-270, 2020. 